\title{
New cut-off values for screening of trisomy 21,18 and open neural tube defects (ONTD) during the second trimester in pregnant women with advanced maternal age
}

Yiming Chen ${ }^{1 *+} \mathbb{D}$, Xue Wang ${ }^{2+}$, Liyao $\mathrm{Li}^{1}$, Sha $\mathrm{Lu}^{1}$ and Zhifen Zhang ${ }^{2 *+}$

\begin{abstract}
Background: To determine whether advanced maternal age (AMA) causes changes in the maternal serum markers of Trisomy 21, 18 and open neural tube defects (ONTD) during the second trimester of pregnancy. Our research aims to develop new cut-off values for AMA in order to reduce the need for further invasive testing.

Methods: This retrospective cohort study involved 12,739 pregnant women with AMA and 197,101 pregnant women with non-AMA. We then compared the two groups with respect to the positive rate and positive predictive value (PPV) of Trisomy 21, 18 and ONTD. Pregnant women with Trisomy 21, 18 and ONTD were diagnosed by karyotyping the amniotic fluid and by ultrasound diagnosis.

Results: Compared to the non-AMA group, the multiple of the median (MOM) of free beta- human chorionic gonadotropin (free $\beta-h C G$ ), alpha-fetoprotein (AFP), and the risk value forTrisomy 21 , were significantly higher in the AMA group (all $P<0.001$ ). The positive rates of Trisomy 21,18 , and ONTD in the AMA group were significantly higher than those in the control group (all $P<0.001$ ). In the AMA group, the PPVs for Trisomy 21 and other deformities were significantly higher (all $P<0.001$ ), although the PPVs for Trisomy 18 and ONTD were similar to those of the non-AMA group. The area under the curve (AUC) values for the AMA group were higher than the nonAMA group, based on free $\beta$-hCG MoM, AFP MoM, and the risk value of Trisomy 21. The cut-off value for the risk value of Trisomy 21 was 1/172 for the AMA, group and 1/780 for the non-AMA group.

Conclusions: The positive rates for Trisomy 21, 18 and ONTD, and the PPV for Trisomy 21 and other deformities were significantly higher in the AMA group. It is essential for pregnant women with AMA to be tested using appropriate cut-off values of serum markers screening for Trisomy 21 during the second trimester of pregnancy to improve the efficacy of prenatal screening and reduce the need for further invasive testing.
\end{abstract}

Keywords: Advanced maternal age;alpha-fetoprotein, Down syndrome, Free beta human chorionic gonadotropin, Positive rate, Positive predictive value (PPV)

\footnotetext{
* Correspondence: cxy40344@163.com; zhangzf@zju.edu.cn

†Yiming Chen, Xue Wang and Zhifen Zhang contributed equally to this work. 'Department of Prenatal Diagnosis and Screening Center, Hangzhou Women's Hospital (Hangzhou Maternity and Child Health Care Hospital), No. 369, kunpeng Road, Shangcheng District, Hangzhou Zhejiang 310008, China ${ }^{2}$ Nanjing Medical University, Nanjing Jiangsu 210029, China
}

C C The Author(s). 2020 Open Access This article is licensed under a Creative Commons Attribution 4.0 International License, which permits use, sharing, adaptation, distribution and reproduction in any medium or format, as long as you give appropriate credit to the original author(s) and the source, provide a link to the Creative Commons licence, and indicate if changes were made. The images or other third party material in this article are included in the article's Creative Commons licence, unless indicated otherwise in a credit line to the material. If material is not included in the article's Creative Commons licence and your intended use is not permitted by statutory regulation or exceeds the permitted use, you will need to obtain permission directly from the copyright holder. To view a copy of this licence, visit http://creativecommons.org/licenses/by/4.0/ The Creative Commons Public Domain Dedication waiver (http://creativecommons.org/publicdomain/zero/1.0/) applies to the data made available in this article, unless otherwise stated in a credit line to the data. 


\section{Background}

Trisomy 21, also referred to as Down's Syndrome (DS) or the 'congenital type', and trisomy 18, which is also known as Edwards' syndrome (ES), are the most common chromosomal abnormalities, with neonatal incidences of 1/800-1/ 600 [1] and 1/2600-1/2500 [2], respectively. Because these conditions both include additional chromosomal material, Trisomy 21 and 18 are characterized by irreversible mental retardation. The survivors of this condition do not generally have the ability to take care of themselves. Moreover, Trisomy 21 and 18 are the most common hereditary causes of low intelligence and account for $90 \%$ of all neonatal chromosomal diseases [1-3]. Open neural tube defects (ONTD) are considered to be serious congenital birth defects and generally occur before 4 weeks of pregnancy. Such defects arise because the neural tube fails to close. There are many forms of ONTD, including cranial dysraphism and spinal dysraphism; the former is fatal and results in abortion, infant death or still birth. In contrast, spinal dysraphism causes symptoms of paralysis and incontinence [4]. Previous research showed that ONTD affects 1.2 per 1000 pregnancies worldwide [5].

Previous studies have shown that women of advanced maternal age (AMA) have a higher incidence of Trisomy $21[6,7]$, although the precise mechanisms underlying these observations remain unclear. Although a range of biomarkers exist for the detection of ONTD and Trisomy 21 , there is an increasing shift towards the use of cell-free DNA (cfDNA) for the detection of fetal aneuploidies. It is possible that the development of such tests may have significant impact upon the ways in which we screen for ONTD and Trisomy 21. Data also appear to suggest that the levels of serum AFP in the pregnant women may represent a potential standalone screen for ONTD only [8]. In a previous study, AMA led to an increase in sister kinetochore separation, rotated bivalents and merotelic attachments, and revealed multiple agerelated changes in chromosome architecture, thus, providing an explanation for the increased levels of oocyte aneuploidy with AMA [9]. Many countries now recommend that pregnant women with a maternal age of 35 years or more should undergo interventional prenatal diagnosis during the second trimester in order to avoid fetuses being born with chromosomal abnormalities and ONTD $[10,11]$. However, some studies have reported that the prenatal screening of serum Trisomy 21 markers in pregnant women of AMA could significantly reduce the probability of interventional prenatal diagnosis $[12,13]$. Indeed, Been et al. suggested that maternal serum screening and ultrasonography, when carried out in the second trimester, resulted in more judicious use of amniocentesis and chorionic villus sampling [14]. However, very few studies have attempted to investigate the precise association between AMA and ONTD.
We conducted a retrospective cohort study and carried out screening for key maternal serum biomarkers in 12, 739 pregnant women with AMA and 197,101 pregnant women with non-AMA. We then compared the two groups with respect to the positive predictive value (PPV) of Trisomy 21, 18 and ONTD. Our aim was to investigate the reliability of maternal serum screening for pregnant women with AMA during the second trimester of pregnancy, and to identify new cut-off values for the Trisomy 21, Trisomy 18 and ONTD to reduce the need of amniocentesis.

\section{Methods}

\section{Study population}

This was a cohort study that was conducted in Hangzhou Women's Hospital, China. The Hangzhou government implements free prenatal screening involving AFP and free $\beta$-hCG tests for patients registered locally and the floating who have lived in the area for more than 6 months. We recruited 209,840 pregnant women from Hangzhou between January 2015 and October 2018. If the expected maternal age at birth was 35 years or older, then the gravidas were allocated to an AMA group (12, 739 cases; $6.07 \%$ ) or a non-AMA group (197,101 cases; 93.97\%).

Pregnant women were included in the study if they were between 15 weeks and 20 weeks 6 days in gestational age, had a singleton pregnancy, and agreed to be screened for Trisomy 21, 18 and ONTD during the second trimester. Pregnant women were excluded for the following reasons: multiple pregnancy, smoking, diabetes, a history of chromosomal abnormalities and congenital abnormalities, infants conceived in vitro, and a range of pregnancy-related diseases, including hypertensive disorders of pregnancy, gestational diabetes mellitus, and intrahepatic cholestasis of pregnancy.

Trisomy 21 and 18were diagnosed by the chromosomal karyotyping of amniotic fluid cells while ONTD was diagnosed by ultrasound. Community nurses also performed a follow-up for each pregnant woman just 1 year after birth to check for aneuploidy and defects. Chromosomal examinations were also carried out for all stillbirths.

\section{Measurements}

Fasting venous blood samples were drawn from each pregnant woman and the samples were separated for 30 min and centrifuged at $2000 \mathrm{~g}$ for $10 \mathrm{~min}$. Separated sera were then placed in a refrigerator at $2-8{ }^{\circ} \mathrm{C}$ and sent for laboratory testing. A 1235 Automatic Immunoassay System (PerkinElmer, Shelton, USA) was used to measure free beta-human chorionic gonadotropin (free $\beta$-hCG) and alpha-fetoprotein (AFP) and the assays were carried out in accordance with standardized protocols. An 
ultrasound system (VolusonE8, GE) was used for prenatal diagnosis.

The risk values of Trisomy 21, 18 and ONTD were calculated by Life Cycle 4.0 software (Perkin Elmer, Wallac, US), taking into account maternal age, gestational age and maternal weight [15]. The cut-off values were as follows: Trisomy $21 \geq 1: 270$; Trisomy $18 \geq 1$ : 350, AFP $\mathrm{MoM} \geq 2.50$, high risk of ONTD [16]. Pregnant women with a high risk of Trisomy 21 and Trisomy 18 were advised to undergo karyotype analysis using the amniotic fluid cells in order to confirm the diagnosis. Women associated with a high risk of ONTD were advised to undergo ultrasound diagnosis. The measured AFP and free $\beta$-hCG levels were expressed as MOM values. These were adjusted by gestational age and maternal weight. If the menstrual period was regular, then gestational age was determined by the last menstrual period. Otherwise, the double-top diameter was used to confirm the gestational age. If pregnant woman had both a top arm diameter and a double top diameter, then we mainly used the top arm diameter to determine gestational age.

\section{Statistical analysis}

All statistical analyses were performed using IBM SPSS Statistical software (version 21.0; Armonk, N.Y.; USA). The one-sample Kolmogorov-Smirnov test was used to test raw data for normality. Tests showed that maternal age, maternal weight, and gestational age, all exhibited a skewed distribution. These data were then expressed as medians and percentiles $\left[\mathrm{M}\left(\mathrm{P}_{2.5}-\mathrm{P}_{97.5}\right)\right]$. The MannWhitney $\mathrm{U}$ test was used to make comparisons between two groups. Comparison of PPV involved the $\chi^{2}$ test or a continuous correction $\chi^{2}$ test. A $P$ value $<0.05$ was considered to be statistically significant.

\section{Results}

Maternal age, maternal weight and gestational age in the AMA group were all significantly higher than in the non-AMA group $(Z=189.464, P<0.001 ; Z=4.883, P<$ $0.001 ; Z=2.261, P<0.001$, respectively; Table 1$)$. The multiple of the median (MoM) value for free $\beta$-hCG, AFP, along with the risk value of Trisomy 21, were all significantly higher in the AMA group than in the nonAMA group $(\mathrm{Z}=6.076, P<0.001 ; \mathrm{Z}=21.964, P<0.001$; $\mathrm{Z}=98.884, P<0.001$, respectively; Table 2 ). The positive rate for cases with a high risk of Trisomy 21, 18 and ONTD in the AMA group were 19.55\% (2490/12739), $1.30 \%(165 / 12739)$, and $0.68 \%(87 / 12739)$, respectively. Those rates were all significantly higher than in the nonAMA group $(5.09 \% \quad(10,037 / 197101), \quad 0.28 \% \quad(559 /$ 197101), $\quad 0.43 \% \quad(839 / 197101)\left(\chi^{2}=4453.316, \quad P<0.001\right.$; $X^{2}=356.143, \quad P<0.001 ; X^{2}=18.027 ; \quad P<0.001$, respectively; Table 3).

Table 4 shows that the PPVs for Trisomy 21, 18, ONTD, and other deformities in the AMA group were $2.20 \%$ o (28/12739), 0.08\%o (1/12739), 0.08\%o (1/12739), and $15.23 \%$ (194/12739), respectively. In the non-AMA group, the PPVs for Trisomy 21, 18, ONTD, and other deformity were $0.24 \%$ (48/197101), 0.08\%o (15/197101), 0.07\% (14/197101), and 8.36\%o (1647/197101), respectively. The PPV for Trisomy 21 and other deformities were significantly different when compared between the AMA and non-AMA groups $\left(\chi^{2}=126.245, P<0.001\right.$; $\left.\chi^{2}=50.329, P<0.001\right)$; however, the PPVs for Trisomy 18 and ONTD were not significantly different.

In the AMA group, the area under curve (AUC) was 0.783, 0.767, and 0.858, for the PPVs for maternal free $\beta$-hCG MoM, AFP MoM, and the risk value of Trisomy 21 , respectively. When the cut-off values were 1.725 MoM, $0.925 \mathrm{MoM}$, and 1/172, respectively, the corresponding sensitivities were $0.679,0.821$, and 0.714 , respectively (Table 5; Fig. 1a). In the non-AMA group, the AUC was $0.784,0.699$ and 0.856 for maternal free $\beta$ hCG MoM, AFP MoM, and the risk value of Trisomy 21 , respectively. When the cut-off values were 2.055 MoM, $0.795 \mathrm{MoM}$, and 1/780, respectively, the corresponding sensitivities were $0.675,0.675$, and 0.792 , respectively (Table 5; Fig. 1b).

In Table 6, the sensitivity, PPV and false positive rate of Trisomy 21 screening for pregnant women in the AMA group were all higher than those in the non-AMA group.

\section{Discussion}

Collectively, the liberalization of the second child policy, and the increasing pressure to work, is leading towards an era of pregnancies in women of AMA. In the USA, the proportion of pregnancies in women of AMA was approximately $5 \%$ in the 1970 s, but rose to $14 \%$ by 2002 . Furthermore, AMA pregnancies accounted for more

Table 1 Basic demographic data of each group

\begin{tabular}{lllll}
\hline Group & $\mathbf{N}$ & maternal age (years) & gestational age (days) & maternal weight $(\mathbf{k g})$ \\
\hline Non-AMA & 197,101 & $28.41(21.54 \sim 34.43)$ & $118.00(108.00 \sim 134.00)$ & $54.50(43.00 \sim 74.60)$ \\
AMA & 12,739 & $36.87(35.05 \sim 42.39)$ & $118.00(109.00 \sim 134.00)$ & $57.50(45.00 \sim 76.50)$ \\
$Z$ & & 189.464 & 4.883 & 2.261 \\
$P$ & $<0.001$ & $<0.001$ & $<0.001$ \\
\hline
\end{tabular}


Table 2 Comparation of maternal serum markers of Trisomy 21 and 18 risk value

\begin{tabular}{lllll}
\hline Group & $\mathbf{N}$ & AFP $(\mathbf{K U} / \mathbf{L})$ & AFP $(\mathbf{M o M})$ & Free $\boldsymbol{\beta}$ - $\mathbf{h C G}(\boldsymbol{\mu g} / \mathbf{L})$ \\
\hline Non-AMA & 197,101 & $37.2(19.20 \sim 75.50)$ & $0.98(0.54 \sim 1.87)$ & $14.30(4.45 \sim 57.20)$ \\
AMA & 12,739 & $37.9(19.30 \sim 77.50)$ & $1.05(0.56 \sim 1.99)$ & $14.30(4.27 \sim 59.75)$ \\
$Z$ & & 6.058 & 21.964 & 1.111 \\
$P$ & $<0.001$ & $<0.001$ & 0.911 \\
Group & Free $\beta-$ hCG $($ MoM) & Risk value of Trisomy 21 & Risk value of Trisomy 18 \\
Non-AMA & $0.99(0.33 \sim 3.60)$ & $1 / 3934(1 / 133 \sim 1 / 33336)$ & $1 / 46055(1 / 2477 \sim 1 / 100000)$ \\
AMA & $1.02(0.33 \sim 3.97)$ & $1 / 1003(1 / 25 \sim 1 / 9648)$ & $1 / 11686(1 / 624 \sim 1 / 44622)$ \\
$z$ & 6.076 & 98.885 & 124.780 \\
$P$ & $<0.001$ & $<0.001$ & $<0.001$ \\
\hline
\end{tabular}

$A M A$ advanced maternal age, AFP alpha-fetoprotein, free $\beta$ - $h C G$ free beta human chorionic gonadotropin, MoM multiple of the median

than $50 \%$ of cases involving Trisomy 21 in 2002 [17]. In our study, we identified 12,739 pregnant women with AMA, accounting for $6.07 \%$ of our study population. The PPV for Trisomy 21 was $2.20 \%$, which was higher than that described in other recent reports (5.46\% AMA and a PPV of 129 per million for Trisomy 21) [18, 19]. Because there are only a small number of medical institutions that are able to carry out prenatal diagnosis, not all pregnant women are able to undergo such testing, or miss the time window to undergo these important tests. Furthermore, some pregnant women are afraid and fail to undergo prenatal diagnosis because they are concerned about the $1.21 \%$ abortion rate that is associated with amniocentesis [20]. The American College of Obstetricians and Gynecologists recommend that regardless of the age of pregnant women, the serum markers for selected aneuploidy conditions should be screened in pregnancy before further interventional prenatal diagnosis [21]. In Tunisia, the guidelines are that serum marker testing should be offered to all patients, including women of AMA, and that routine amniocentesis for women of AMA should be avoided [22]. Collectively, these studies demonstrate the necessity for serum prenatal screening for Trisomy 21 in women of AMA.

Because factors related to maternal age are included in the risk calculation for Trisomy 21 and 18 [23], the MoM value for free $\beta$-hCG and AFP, and the risk values for Trisomy 21, in women of AMA were significantly higher than in the non-AMA group (all $P<0.001$ ). Furthermore, the positive rates for a high risk of Trisomy
21, 18and ONTD in the AMA group were significantly higher than in the non-AMA group (all $P<0.001$ ). The positive rates for a high risk of Trisomy 21 in the AMA and non-AMA groups were 19.55 and $5.09 \%$ respectively. These data were similar to the data reported previously by Gyselaers et al. [24] study. We found that the PPVs for Trisomy 21, 18, ONTD, and other deformities in women of AMA were higher than in the non-AMA group. The PPVs for Trisomy 21 and other deformities were both significantly different when compared between the two groups (all $P<0.001$ ).

The PPV for other deformities in women of AMA were $15.23 \%$ o (194/12739) in our study, including 26 chromosomal abnormalities with a PPV of $2.04 \%$ (26/ 12739). These results suggested that maternal serum markers are not only useful for screening Trisomy 21, 18 , and ONTD, but are also useful for screening other diseases, including chromosomal abnormalities. The PPVs for Trisomy 18 and ONTD was not significantly different when compared between the two groups, which may be related to the low number of ES and ONTD in the AMA group, and therefore, needs further verification. Resta et al. previously found that offering amniocentesis to women who were 35-years-of-age and above would result in one in seven of the pregnant women subsequently undergoing amniocentesis [17]. Based on likelihood ratios, using AMA as a screening strategy for Trisomy 21 is significantly inferior to a combination of serum and sonographic screening. Therefore, it is necessary to strengthen the management of high-risk and

Table 3 Comparation of results of prenatal screening

\begin{tabular}{|c|c|c|c|c|c|c|c|}
\hline \multirow[t]{2}{*}{ Group } & \multicolumn{3}{|l|}{ High risk } & \multicolumn{3}{|l|}{ Low risk } & \multirow[t]{2}{*}{ Sum } \\
\hline & Trisomy 21 & Trisomy 18 & ONTD & Trisomy 21 & Trisomy 18 & ONTD & \\
\hline Non-AMA & $10,037(5.09)$ & $559(0.28)$ & $839(0.43)$ & $187,064(94.91)$ & $196,542(99.72)$ & $196,262(99.57)$ & 197,101 \\
\hline AMA & 2490 (19.55) & $165(1.30)$ & 87 (0.68) & $10,249(80.45)$ & $12,574(98.70)$ & $12,652(99.32)$ & 12,739 \\
\hline Sum & $12,527(5.97)$ & $724(0.35)$ & $926(0.44)$ & $197,313(94.03)$ & 209,116 (99.65) & $208,914(99.56)$ & 209,840 \\
\hline
\end{tabular}

AMA advanced maternal age, ONTD Open neural tube defects 


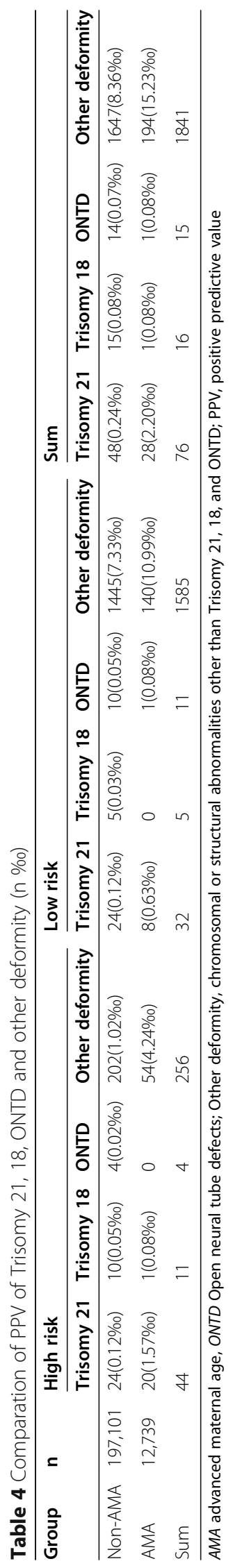


Table 5 Predictive values of maternal free $\beta$ - hCG, AFP MoM, and risk value of Trisomy 21 for Trisomy 21

\begin{tabular}{|c|c|c|c|c|c|c|c|c|}
\hline Group or item & $\mathbf{N}$ & AUC & $95 \% \mathrm{Cl}$ & $P$ & cut-off & Sensitivity & Specificity & Youden index \\
\hline Non-AMA & 197,101 & & & & & & & \\
\hline free $\beta$ - hCG (MoM) & & 0.784 & $0.703-0.865$ & $<0.001$ & 2.055 & 0.675 & 0.881 & 0.506 \\
\hline AFP (MoM) & & 0.699 & $0.618-0.779$ & $<0.001$ & 0.795 & 0.675 & 0.760 & 0.385 \\
\hline Risk value of Trisomy 21 & & 0.856 & $0.792-0.920$ & $<0.001$ & $1 / 780$ & 0.792 & 0.862 & 0.654 \\
\hline AMA & 12,739 & & & & & & & \\
\hline free $\beta$ - hCG (MoM) & & 0.783 & $0.680-0.885$ & $<0.001$ & 1.725 & 0.679 & 0.805 & 0.483 \\
\hline AFP (MoM) & & 0.767 & $0.668-0.865$ & $<0.001$ & 0.925 & 0.821 & 0.656 & 0.477 \\
\hline Risk value of Trisomy 21 & & 0.858 & $0.780-0.936$ & $<0.001$ & $1 / 172$ & 0.714 & 0.866 & 0.580 \\
\hline
\end{tabular}

AMA advanced maternal age, AFP alpha-fetoprotein, free $\beta$ - $h C G$ free beta human chorionic gonadotropin, MoM multiple of the median

low-risk pregnant women during the late stages of prenatal screening, particularly in terms of the sonographic screening strategies.

We found that the combination of serum screening with maternal age in the second trimester was more effective than using maternal age alone to screen for Trisomy 21. Prenatal ultrasonography for soft markers of chromosomal aneuploidy, accompanied by maternal serum biochemical screening tests, should be evaluated during the decision-making process when considering genetic amniocentesis in women of AMA. Patients should be educated by recommending women of AMA to be informed of both screening and amniocentesis options $[25,26]$. We also found that the AUCs were 0.783, 0.767 and 0.858 , respectively, for the PPVs of free $\beta$-hCG MoM, AFP MoM, and the risk value for Trisomy 21 in women of AMA. These PPVs were significantly higher than the corresponding AUCs for the non-AMA group $(0.784,0.699$, and 0.856$)$. With a similar sensitivity, the cut-off values for the risk value of Trisomy 21 was $1 / 172$, much higher than the risk value of the nonAMA group (1/780). This indicated that if the cut-off value for the non-AMA group was applied to judge all pregnant women, then between $1 / 172$ and 1/780 pregnancies would undergo amniocentesis, thus, causing interventional prenatal diagnosis that was unnecessary.

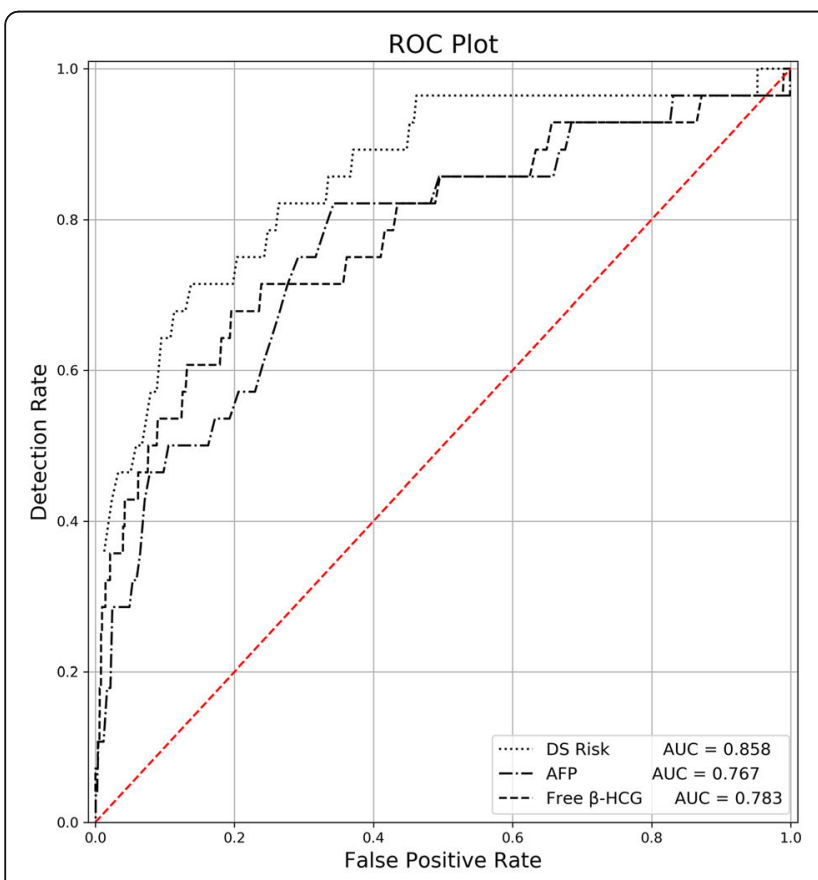

(a) AMA

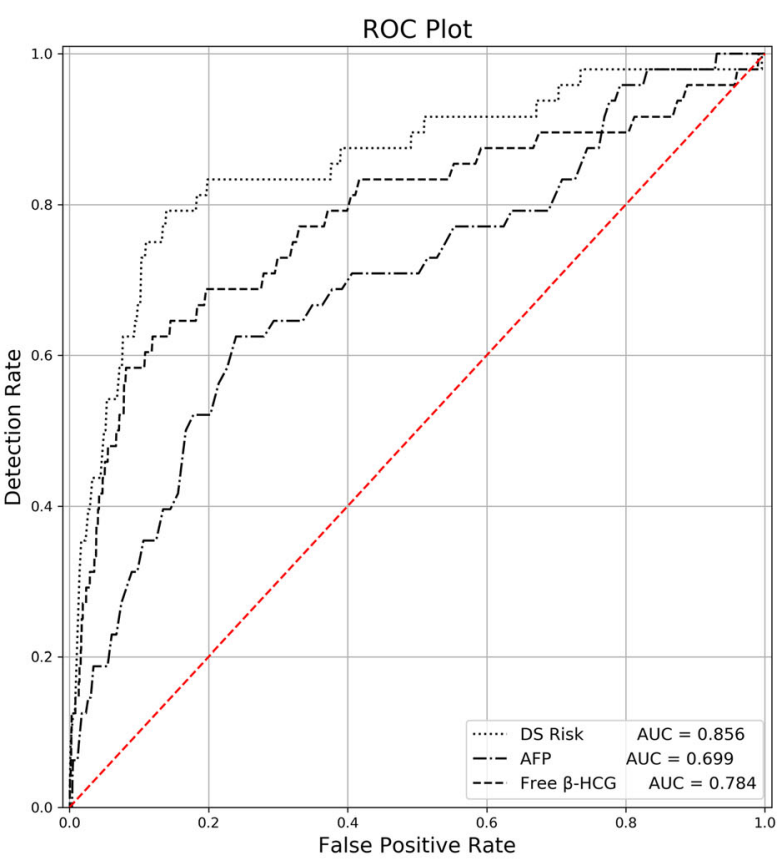

(b) non-AMA

Fig. 1 AUC of maternal free $\beta-h C G$ MoM, AFP MoM and risk value of Trisomy 21 for Trisomy 21 in ROC curves. a AUC of AMA; b AUC of non-AMA 
Table 6 Predicted value and diagnostic value of prenatal screening for Trisomy 21 (\%)

\begin{tabular}{llllllll}
\hline Group & $\begin{array}{l}\text { Screening } \\
\text { for disease }\end{array}$ & Sensitivity & Specificity & $\begin{array}{l}\text { Positive predictive } \\
\text { value }\end{array}$ & $\begin{array}{l}\text { Negative predictive } \\
\text { value }\end{array}$ & $\begin{array}{l}\text { False positive } \\
\text { rate }\end{array}$ & $\begin{array}{l}\text { False negative } \\
\text { rate }\end{array}$ \\
\hline AMA & Trisomy 21 & 71.43 & 80.56 & 0.80 & 99.92 & 19.43 & 28.57 \\
Non-AMA & Trisomy 21 & 50.00 & 94.92 & 0.24 & 99.99 & 5.08 & 50.00 \\
\hline
\end{tabular}

\section{Conclusions}

We found that with regards to maternal serum screening, the positive rate for a high risk in women of AMA was significantly higher than that of younger pregnant women. The PPVs for Trisomy 21 and other malformations were both higher in women of AMA than the nonAMA group. It is essential that we significantly reduce the number of unnecessary interventional prenatal diagnoses and improve the efficacy of prenatal screening.

\author{
Abbreviations \\ AMA: Advanced maternal age; NT: Nuchal translucency; AFP: Alpha- \\ fetoprotein; free $\beta$-hCG: Free beta human chorionic gonadotropin; \\ MoM: Multiple of the median; DS: Down's Syndrome; ES: Edwards' syndrome; \\ ONTD: Open neural tube defects; AUC: Area under curve; PPV: Positive \\ predictive value
}

\section{Acknowledgements}

The authors are grateful to all participants and contributors. Thank to Xiao Lu, Qingxin Xiao, Yezhen Shi and Shaolei Lv of the Data Analysis Department of Zhejiang Biosan Biochemical Technologies Co., Ltd. We thank International Science Editing (http: //www. Internationalscienceediting. com) for editing this manuscript.

\section{Authors' contributions}

YMC, XW, and ZFZ conceptualized and refined the study design and methodology. LYL conducted data programming. YMC and SL conducted all analyses and prepared tables and figures with assistance from Data Analysis Department. XW wrote the entire manuscript and performed literature review. All authors read and approved the final manuscript.

\section{Funding}

The data collected and analyzed for this study and the secondary editing for the manuscript was carried out with support provided by Zhejiang Natural Science Foundation/Public Welfare Technology Research Plan/Social Development (LGF19H040006); Hangzhou Science and Technology Plan Guide Project/Agriculture and Social Development (20181228Y13); Hangzhou Health Science and Technology Plan Project (2017A55). The funding bodies played no role in the design of the study and collection, analysis, and interpretation of data and in writing the manuscript.

\section{Availability of data and materials}

All data generated or analyzed during this study are included in the supplementary file and this published article.

\section{Ethics approval and consent to participate}

The study was approved by Hangzhou Women's Hospital (Hangzhou Maternity and Child Health Care Hospital) ethics committee, and the approval number was [2018] medical ethics (004) No.01. The data used in this study was anonymised before its use. Patients' consents were not required because this was a retrospective study.

\section{Consent for publication}

Not applicable; this was a retrospective study and no individual person's personal information is included.

\section{Competing interests}

The authors declare that they have no competing interests.
Received: 26 February 2020 Accepted: 30 November 2020

Published online: 14 December 2020

\section{References}

1. Webster A, Schuh M. Mechanisms of aneuploidy in human eggs. Trends Cell Biol. 2017;27(1):55-68.

2. Cereda A, Carey JC. The trisomy 18 syndrome. Orphanet J Rare Dis. 2012;7:81.

3. Wang S, Hassold T, Hunt P, White MA, Zickler D, Kleckner N, Zhang L. Inefficient crossover maturation underlies elevated aneuploidy inHuman female meiosis. Cell. 2017;168(6):977-89.

4. Salih MA, Murshid WR, Seidahmed MZ. Classification, clinical features, and genetics of neural tube defects. Saudi Med J. 2014;35(Suppl 1):S5-S14.

5. Seidahmed MZ, Abdelbasit OB, Shaheed MM, Alhussein KA, Miqdad AM, Khalil MI, Al-Enazy NM, Salih MA. Epidemiology of neural tube defects. Saudi Med J. 2014;35(Suppl1):S29-35.

6. Ocak Z, Ozlu T, Yazicioglu HF, Ozyurt O, Aygun M. Clinical and cytogenetic results of a large series of amniocentesis cases from Turkey: report of 6124 cases. J Obstet Gynaecol Res. 2014;40(1):139-46.

7. Evans MI, Wapner RJ, Berkowitz RL. Noninvasive prenatal screening or advanced diagnostic testing: caveat emptor. Am J Obstet Gynecol. 2016; 215(3):298-305.

8. Palomaki GE, Bupp C, Gregg AR, Norton ME, Oglesbee D, Best RG. Laboratory screening and diagnosis of open neural tube defects, 2019 revision: a technical standard of the American College of Medical Genetics and Genomics (ACMG). Genet Med. 2020;22(3):462-74.

9. Zielinska AP, Holubcova Z, Blayney M, Elder K, Schuh M. Sister kinetochore splitting and precocious disintegration of bivalents could explain the maternal age effect. Elife. 2015;4:e11389.

10. Grinshpun-Cohen J, Miron-Shatz T, Berkenstet M, Pras E. The limited effect of information on Israeli pregnant women at advanced maternal age who decide to undergo amniocentesis. Isr J Health Policy Res. 2015;4:23.

11. Hagen A, Entezami M, Gasiorek-Wiens A, Albig M, Becker R, Knoll U, Stumm $M$, Wegner RD. The impact of first trimester screening and early fetal anomaly scan on invasive testing rates in women with advanced maternal age. Ultraschall Med. 2011;32(3):302-6.

12. Sun $Q, X u Z$ Z, Bai X, Li D. Analysis of screening and prenatal diagnosis of Down syndrome in the second trimester of pregnancy in Guangzhou. Int J Lab Med. 2015;36(14):2113-4 [Artile in Chinese].

13. Nakata N, Wang $Y$, Bhatt S. Trends in prenatal screening and diagnostic testing among women referred for advanced maternal age. Prenat Diagn. 2010;30(3):198-206.

14. Benn PA, Egan JF, Fang M, Smith-Bindman R. Changes in the utilization of prenatal diagnosis. Obstet Gynecol. 2004;103(6):1255-60.

15. Bock JL. Current issues in maternal serum alpha-fetoprotein screening. Am J Clin Pathol. 1992;97(4):541-54.

16. The Professional Committee of Medical Service Standards of the Ministry of Health. Technical Standards for Prenatal Screening and Diagnosis of Common Fetal Chromosome Abnormalities and Open Neural Tube Defects, 2010-10-01. Article in Chinese.

17. Resta RG. Changing demographics of advanced maternal age (AMA) and the impact on the predicted incidence of Down syndrome in the United States: implications for prenatal screening and genetic counseling. Am J Med Genet A. 2005;133A(1):31-6.

18. Qi QW, Jiang YL, Liu JT, Bian XM, Li Y, Lu SM, Zhu BS, Wang H, Xu ZF, Pan $X Y$, et al. Second trimester maternal serum screening for Down's syndrome in women of advanced maternal age: a multi-center prospective study. Zhonghua Fu Chan Ke Za Zhi. 2008;43(10):737-41.

19. Wright CF, Burton $\mathrm{H}$. The use of cell-free fetal nucleic acids in maternal blood for non-invasive prenatal diagnosis. Hum Reprod Update. 2009;15(1): 139-51.

20. Kurtovic-Kozaric A, Mehinovic L, Malesevic R, Mesanovic S, Jaros T, Stomornjak-Vukadin M, Mackic-Djurovic M, Ibrulj S, Kurtovic-Basic I, Kozaric 
M. Ten-year trends in prevalence of Down syndrome in a developing country: impact of the maternal age and prenatal screening. Eur J Obstet Gynecol Reprod Biol. 2016;206:79-83.

21. Practice Bulletin No ACOG 77. Screening for fetal chromosomal abnormalities. Obstet Gynecol. 2007;109(1):217-27.

22. Chelli D, Dimassi K, Chaabouni M, Ben SM, Mssaed H, Bchir F, Zouaoui B, Sfar E, Gaigi S, Chelli H, et al. Prenatal diagnosis of trisomy 21: the Tunisian experience. Sante. 2008;18(4):199-203.

23. Cuckle HS, Wald NJ, Thompson SG. Estimating a woman's risk of having a pregnancy associated with Down's syndrome using her age and serum alpha-fetoprotein level. Br J Obstet Gynaecol. 1987:94(5):387-402.

24. Gyselaers WJ, Vereecken AJ, van Herck E, Straetmans DP, de Jonge ET, Ombelet WU, Nijhuis JG. Single-step maternal serum screening for trisomy 21 in the era of combined or integrated screening. Gynecol Obstet Investig. 2004:58(4):221-4.

25. Qi QW, Jiang YL, Zhou XY, Liu JT, Yin J, Bian XM. Genetic counseling, prenatal screening and diagnosis of Down syndrome in the second trimester in women of advanced maternal age: a prospective study. Chin Med J. 2013;126(11):2007-10.

26. Danisman N, Kahyaoglu S, Celen S, Kahyaoglu I, Candemir Z, Yesilyurt A, Cakar ES. A retrospective analysis of amniocenteses performed for advanced maternal age and various other indications in Turkish women. J Matern Fetal Neonatal Med. 2013;26(3):242-5.

\section{Publisher's Note}

Springer Nature remains neutral with regard to jurisdictional claims in published maps and institutional affiliations.

Ready to submit your research? Choose BMC and benefit from:

- fast, convenient online submission

- thorough peer review by experienced researchers in your field

- rapid publication on acceptance

- support for research data, including large and complex data types

- gold Open Access which fosters wider collaboration and increased citations

- maximum visibility for your research: over $100 \mathrm{M}$ website views per year

At $\mathrm{BMC}$, research is always in progress.

Learn more biomedcentral.com/submissions 